Article

\title{
Development, Characterization and In Vitro Evaluation of Paclitaxel and Anastrozole Co-Loaded Liposome
}

\author{
Minh Thanh Vu ${ }^{1}{ }^{(D}$, Dinh Tien Dung Nguyen ${ }^{2,3}$, Ngoc Hoi Nguyen ${ }^{3}{ }^{(0)}$, Van Thu Le ${ }^{3} \mathbb{C D}$, \\ The Nam Dao ${ }^{1}$, Thi Huong Nguyen ${ }^{1}{ }^{1}$, Tien Dung Cong ${ }^{4}{ }^{-}$, Truc Le-Buu Pham ${ }^{5}$, Tri Duc Lam ${ }^{6}$ \\ and Ngoc Thuy Trang Le ${ }^{7, *(\mathbb{D})}$ \\ 1 Institute for Chemistry and Materials, 17 Hoang Sam, Cau Giay, Hanoi City 100000, Vietnam; \\ Vuminhthanh@vienhoahocvatlieu.com.vn (M.T.V.); namke@mail.ru (T.N.D.); \\ nguyenhuong0916@gmail.com (T.H.N.) \\ 2 Graduate University of Science and Technology, Vietnam Academy of Science and Technology, \\ Hanoi City 100000, Vietnam; tiendungnguyen2201@gmail.com \\ 3 Institute of Applied Materials Science, Vietnam Academy of Science and Technology, \\ Ho Chi Minh City 700000, Vietnam; hoi83bmt@gmail.com (N.H.N.); thulv81@yahoo.com (V.T.L.) \\ 4 Hanoi University of Mining and Geology, 18 Pho Vien, Duc Thang, Tu Liem, Hanoi City 100000, Vietnam; \\ congtiendung@humg.edu.vn \\ 5 Biotechnology Center of Ho Chi Minh City, 2374, Highway 1, Trung My Tay Ward, District 12, \\ Ho Chi Minh City 700000, Vietnam; buutruc@hcmbiotech.com.vn \\ 6 NTT Hi-Tech Institute, Nguyen Tat Thanh University, Ho Chi Minh City 700000, Vietnam; ltduc@ntt.edu.vn \\ 7 Institute of Research and Development, Duy Tan University, Danang 550000, Vietnam \\ * Correspondence: lenthuytrang4@duytan.edu.vn
}

Received: 6 June 2020; Accepted: 4 September 2020; Published: 6 September 2020

check for updates

\begin{abstract}
Paclitaxel (PTX) and anastrozole (ANA) have been frequently applied in breast cancer treatment. PTX is well-known for its anti-proliferative effect meanwhile ANA has just been discovered to act as an estrogen receptor $\alpha(\mathrm{ER} \alpha)$ ligand. The combination therapy of PTX and ANA is expected to improve treating efficiency, as ANA would act as a ligand binding with the ER $\alpha$ gene expressed in breast cancer cells and thereafter PTX would inhibit the division and cause death to those cancer cells. In this study, liposome-based nanocarriers (LP) were developed for co-encapsulation of PTX and ANA to improve the efficacy of the combined drugs in an Estrogen receptor-responsive breast cancer study. PTX-ANA co-loaded LP was prepared using thin lipid film hydration method and was characterized for morphology, size, zeta potential, drug encapsulation and in vitro drug release. In addition, cell proliferation (WST assay) and IN Cell Analyzer were used for in vitro cytotoxicity studies on a human breast cancer cell line (MCF-7). Results showed that the prepared LP and PTX-ANA-LP had spherical vesicles, with a mean particle size of $170.1 \pm 13.5 \mathrm{~nm}$ and $189.0 \pm 22.1 \mathrm{~nm}$, respectively. Controlled and sustained releases were achieved at $72 \mathrm{~h}$ for both of the loaded drugs. The in vitro cytotoxicity study found that the combined drugs showed higher toxicity than each single drug separately. These results suggested a new approach to breast cancer treatment, consisting of the combination therapy of PTX and ANA in liposomes based on ER response.
\end{abstract}

Keywords: paclitaxel; anastrozole; co-loaded; soy lecithin liposome; drug delivery system

\section{Introduction}

In breast cancer treatment, paclitaxel (PTX) and anastrozole (ANA) are two of the chemotherapy agents that have been applied the most frequently [1]. Paclitaxel is classified as a microtubule-stabilizing 
agent, and has been reported to exhibit its anti-proliferative effect through binding to the N-terminal 31 amino acids of the $\beta$-tubulin subunit in the microtubule, consequently stabilizing the microtubule and increasing the microtubule polymerization, which in turn leads to cell cycle arrest [2]. Usually, PTX is used after surgery to reduce the risk of early-stage breast cancer coming back and treat advanced-stage breast cancer after it stops responding to standard chemotherapy regimens that include an anthracycline [3-6]. Anastrozole, on the other hand, has been assumed to inhibit tumor growth only through decreasing estrogen production by inhibiting aromatase [7-10]. Interestingly, Ingle and co-workers have just published their study in Clinical Cancer Research, a qualified medical journal, reporting that among aromatase inhibitors (anastrozole, exemestane and letrozole), only anastrozole could directly bind to the estrogen receptor $\alpha$. This finding was based on a pharmacokinetic and pharmacodynamic study on 649 patients; the mechanism of action was then determined by a series of preclinical laboratory experiments including luciferase activity, cell proliferation, radio-labeled ligand estrogen receptor binding, surface plasmon resonance ligand receptor binding, and nuclear magnetic resonance assays [11]. This report suggested a new approach to breast cancer treatment that exploited ANA as an estrogen receptor $\alpha$ ligand.

In recent years, the co-delivery of multiple chemotherapeutic agents, which loads drugs with different pharmacological mechanisms into a combination delivery system, has been particularly promising for improving anticancer efficacy. It is known that such a treatment on tumors allows each drug to be used in an optimal dose while reducing side effects. In previous research, the performance of the single encapsulation of PTX or ANA into a drug delivery system has already been thoroughly investigated [12-16]. These results indicated that it needs a high pharmacokinetic volume of distribution and rapid elimination rates, requiring more frequent and high dose administration. Therefore, a co-delivery system may help solve the problems associated with the current single-agent chemotherapy, which often cannot achieve entire tumor remission due to this remission being short-lived due to the rapid elimination rate of the compound. More importantly, with the action mechanisms of PTX and ANA presented above, the combination therapy of PTX and ANA is expected to greatly increase treatment efficiency, as ANA would act as a ligand binding with the ER $\alpha$ gene expressed in breast cancer cells and thereafter PTX would inhibit the division and cause death to those cancer cells.

Discovered in the early 1960s, liposomes (LP) have been known as one of the most promising encapsulations used in targeted and controlled release technologies as part of the speedily developing field of nanomedicine. Structured by one or two phospholipid bilayers surrounding an aqueous solution core, liposomes have been revealed to be good systems for the co-delivery of drugs with different characteristics [17-22]. At the same time, the human breast cancer cell line MCF-7, which is classified as estrogen receptor-positive breast cancer cells, has been widely used in many laboratories for biological studies [23]. The expression of the estrogen receptor $\alpha$ gene (ER $\alpha)$ in the MCF-7 cell line was determined to be nearly $300 \mathrm{fmol} / \mathrm{mg}$ of protein. Therefore, MCF-7 can be used as a model cell line for scientists to develop an effective chemotherapy via ER $\alpha$ ligands [24].

In this study, PTX was co-loaded with ANA into LP in order to develop a nanocarrier-delivered form of combination therapy for the study of ER-responsive breast cancer. Dynamic light scattering (DLS), zeta potential measurement, and transmission electron microscopy (TEM) were carried out to characterize the morphology of the prepared LP and PTX-ANA-LP. An in vitro drug release profile was performed using the dialysis method. The cytotoxic effects of individual and combined drugs on the MCF-7 cell line were evaluated using the cell proliferation assay WST-1. This study promises to contribute a new and effective approach to breast cancer treatment.

\section{Materials and Methods}

\subsection{Materials}

Paclitaxel (PTX) was purchased from Samyang Corporation (Seoul, Korea). Anastrozole (ANA) was synthesized at the Institute of Applied Material Science (IAMS, Ho Chi Minh City, Vietnam). 
Cholesterol (CHO) and mannitol were purchased from Sigma Aldrich (St Louis, MO, USA). Soy lecithin (SL) and Tween 80 (polyoxyethylene sorbitan monooleate) were purchased from TCI Co., LTD (Tokyo, Japan). Cetyltrimethylammonium bromide (CTAB) and High-performance liquid chromatography (HPLC)-grade solvents were obtained from Merck (Darmstadt, Germany).

Dulbecco's modified Eagle medium: nutrient mixture F-12 (DMEM/F12), penicillin, streptomycin and trypsin/EDTA were purchased from Thermo Fisher Scientific (Waltham, Massachusetts, USA). Fetal bovine serum (FBS) was purchased from Wisent (Saint-Bruno, QC, Canada). A WST-1 assay kit was purchased from Sigma Aldrich (St Louis, MO, USA). The human breast cancer cell line (MCF-7) was obtained from The University of Tsukuba (Tsukuba, Ibaraki, Japan), and was purchased from ATCC (American Type Culture collection, Manassas, Virginia, USA) [25]. The cells were cultured in DMEM/F12 medium containing 10\% FBS, $2 \%$ penicillin/streptomycin $(10,000 \mathrm{U} / \mathrm{mL}$ penicillin and $10 \mathrm{mg} / \mathrm{mL}$ streptomycin) at $37^{\circ} \mathrm{C}$ in a humidified incubator that was supplemented with $5 \% \mathrm{CO}_{2}$.

All chemicals and solvents were either of the highest analytical grade or the best possible pharma grade and were used as supplied.

\subsection{Methods}

\subsubsection{Preparation of PTX and ANA Co-Loaded Liposome}

The thin film hydration method was adopted to prepare the blank LP. To be specific, the composition of the LP prepared was SL:CHO taken in the ratio of 9:1 and 1\% CTAB and dissolved in a chloroform:methanol mixture $(2: 1, v / v)$. The chloroform and methanol solvent were removed by rotary evaporation, followed by vacuuming overnight. The thin film was hydrated in deionized water $\left(\mathrm{deH}_{2} \mathrm{O}\right.$ ) containing $0.5 \%$ Tween $80(\mathrm{v} / \mathrm{v})$ for $2 \mathrm{~h}$ at $60^{\circ} \mathrm{C}$, and then sonicated for $30 \mathrm{~min}$. The suspension was further homogenized using a mini-extruder (EmulsiFlex-05 homogenizer, Avestin Inc., Ottawa, ON, Canada) for 10 cycles. Finally, the collected LP was lyophilized using Mannitol as cryoprotectants and stored at $-8{ }^{\circ} \mathrm{C}$.

PTX-ANA-LP was prepared as the blank LP with hydrophobic drugs (i.e., PTX and ANA), SL, $\mathrm{CHO}$, and CTAB dissolved in chloroform-methanol (2:1 v/v). The solvents were then removed using a rotary evaporator. The thin film was hydrated in $\mathrm{deH}_{2} \mathrm{O}$ containing $0.5 \%$ Tween $80(v / v)$ for $2 \mathrm{~h}$ at $60{ }^{\circ} \mathrm{C}$, followed by intermittent probe sonication. The suspensions were kept, during sonication, in an ice bath, which allowed to keep the average temperature of the samples equal to room temperature. These experimental conditions allowed to maintain the structural characteristics of the liposome as evidenced also in the case of a previous study [26]. Then, they were further homogenized by a mini-extruder (EmulsiFlex-05 homogenizer, Avestin Inc., Ottawa, ON, Canada) for 10 cycles. The total weight of drugs accounted for $5 \%$ of the LP weight. The production process of the LP is presented in flow chart form in the Supplementary Materials (Figure S1).

\subsubsection{Characterization}

The size, size distribution (polydispersity index, PDI) and zeta potential of the LP and PTX-ANA-LP were characterized using a Zetasizer Nano SZ (SZ-100, Horiba). The size profile was determined by dynamic light scattering (DLS). Briefly, $50 \mu \mathrm{L}$ aliquot was diluted and stirred for $15 \mathrm{~min}$ in $5 \mathrm{~mL}$ of $\mathrm{deH}_{2} \mathrm{O}$ and measured at the detection angle of $90^{\circ}$ and the temperature of $25^{\circ} \mathrm{C}$ using a helium-neon $(\mathrm{He}-\mathrm{Ne})$ laser beam for size, $\mathrm{PDI}$, and zeta potential determination in triplicate.

The morphology of the LP and PTX-ANA-LP were observed with a JEM-1400 transmission electron microscope (TEM) (300 kV; JEOL, Tokyo, Japan). The samples were prepared by placing a drop of solution in $\mathrm{deH}_{2} \mathrm{O}(1 \mathrm{mg} / \mathrm{mL})$ onto a carbon-copper grid (300-mesh, TedPella, Inc., 4595 Mountain Lakes Blvd, Redding, CA 96003, USA) and air-drying for 10 min. 


\subsubsection{Drug Loading and Entrapment Efficiency}

Entrapment efficiency (EE) is defined as the ratio of the amount of drug encapsulated in the liposome to that of the total drug in the LP. The ultracentrifuge method was employed to quantify the weight of the drug encapsulated in the liposome. To be specific, aliquots $(0.1 \mathrm{~mL}$ each) of the LP suspensions were diluted to $1.1 \mathrm{~mL}$ via phosphate buffered saline (PBS) ( $\mathrm{pH} 7.4$ ), followed by the removal of released drug particles by centrifugation at $1000 \mathrm{rpm}$ for $10 \mathrm{~min}$ at $25^{\circ} \mathrm{C}$ [27]. Then, ultracentrifugation at 16,000 rpm for $30 \mathrm{~min}$ was performed to precipitate $1 \mathrm{~mL}$ of the LP supernatant, which was then decanted and washed twice with PBS (pH 7.4). The LP pellets were then dissolved with $6 \mathrm{~mL}$ solvent and sonicated for $10 \mathrm{~min}$ to determine the weight of the drug encapsulated in the LP. Then $1 \mathrm{~mL}$ LP suspensions were dissolved with $6 \mathrm{~mL}$ solvent and sonicated for $10 \mathrm{~min}$ to determine the weight of the total drug in the LP. The percentage of the encapsulated drugs was determined spectrophotometrically using Flexar PDA Plus LC Detector (PerkinElmer, USA) HPLC, which consisted of a Model FX-20 Pump, a Model UHPLC injector, and a Model Plexar PDA Plus detector (PerkinElmer, 68 Elm St, Hopkinton, MA 01748, USA) connected to the Chromera ${ }^{\circledR}$ chromatography data system (CDS) software. Separations were performed using a $15 \mathrm{~cm} \times 4.6 \mathrm{~mm} \times 5 \mu \mathrm{m}$ C18 column (PerkinElmer, 68 Elm St, Hopkinton, MA 01748, USA). The mobile phase was acetonitrile:water $=40: 60(v / v)$, filtered and degassed by suction-filtration through a nylon membrane in isocratic flow. The flow rate was $1 \mathrm{~mL} / \mathrm{min}$ and the injection volume was $80 \mu \mathrm{L}$. Briefly, the drug $(1 \mathrm{mg}$ in $10 \mathrm{~mL}$ of acetonitrile:water, $1: 1 \mathrm{v} / \mathrm{v}$ ) was injected to determine the standard curve for this compound. The eluate absorbance was monitored at $214 \mathrm{~nm}$ for PTX and $227 \mathrm{~nm}$ for ANA. The calibration curve of PTX was observed to be linear in the range of $2.5-50 \mu \mathrm{g} / \mathrm{mL}$ with $\mathrm{R}^{2}=0.9997$ and that of ANA was discovered to be linear in the range of $0-50 \mu \mathrm{g} / \mathrm{mL}$ with $\mathrm{R}^{2}=0.9991$. The entrapment efficiency (EE) and drug loading content (DL) were determined as follows:

$$
\begin{aligned}
& \text { EE }(\%)=\frac{\text { Weight of drug encapsulated in LP }}{\text { Weight of total drug in LP }} \times 100 \\
& \text { DL }(\%)=\frac{\text { Weight of encapsulated drug in LP }}{\text { Weight of LP and drug }} \times 100
\end{aligned}
$$

where each indicator was expressed as mean \pm standard deviation, determined through calculations from three separate liposome suspensions. The statistical evaluation of the data was performed using Microsoft ${ }^{\circledR}$ Excel.

\subsubsection{In Vitro Drugs Release}

The dialysis method was used to determine the in vitro release profile of drugs from LP in PBS $(0.01 \mathrm{M}, \mathrm{pH} 7.4)$ at $37^{\circ} \mathrm{C}$. Firstly, PBS containing $2 \%$ Tween 80 was prepared and added with $1 \mathrm{~mL}$ of liposomes. Then, a dialysis bag (MWCO $3.5 \mathrm{kDa}$, Spectrum Laboratories, Inc., Rancho Dominguez, CA, USA) containing the mixture was immersed in vials containing $10 \mathrm{~mL}$ of release medium at 37 ${ }^{\circ} \mathrm{C}$. The vials were maintained at $37^{\circ} \mathrm{C}$ and shaken horizontally at $100 \mathrm{rpm}$ in an orbital shaker bath. At specific time intervals, $1 \mathrm{~mL}$ of the release medium was collected and equally substituted by fresh release medium. Controls containing free PTX and free ANA were prepared in the amount equal to the amount of the drug contained in the liposome and tested along with the liposomal dispersions. The collected samples were filtered (pore size $=0.22 \mu \mathrm{m}$ ) before being analyzed using HPLC.

\subsubsection{Cytotoxicity Study in MCF-7 Cell Line}

The formulations and the control groups were evaluated for cytotoxicity in MCF-7 cell lines cultivated, separately, in DMEM/F12 media supplemented with $2 \mathrm{mM} \mathrm{L-glutamine,} 1.5 \mathrm{~g} / \mathrm{L}$ sodium bicarbonate, $10 \%$ fetal bovine serum, and $2 \%$ penicillin-streptomycin $(10,000 \mathrm{U} / \mathrm{mL}$ penicillin and $10 \mathrm{mg} / \mathrm{mL}$ streptomycin). The cytotoxicity was evaluated through the WST- 1 assay kit. Briefly, cells were seeded at a density of $3 \times 10^{4}$ cells/well into 96 -well culture plates and incubated in an $5 \% \mathrm{CO}_{2}$ incubator 
for $24 \mathrm{~h}$ for seeding. After this period, the cells were treated with reagents at a concentration of $1 \mu \mathrm{g} / \mathrm{mL}$ drug for $24 \mathrm{~h}$; then, $10 \mu \mathrm{L}$ of WST was added to each well and incubated for $4 \mathrm{~h}$ at $37^{\circ} \mathrm{C}$. Microplates were shaken and absorbance was read at $450 \mathrm{~nm}$ using an IN Cell Analyzer 2500HS. The results were expressed as a percentage of viable cells in comparison to the control (taken as $100 \%$ ).

\section{Results and Discussion}

\subsection{Characterization of Multi-Drug Loaded Liposome}

\subsubsection{Particle Size and Zeta Potential}

In assaying the effectiveness of nanoparticles in general, and of liposome in particular, size is one critical parameter among others. Normally, the nanoscale of a delivery structure will help it to avoid being taken up by the bodily mechanism and then be eliminated, and hence enable the carrier structure to establish its effectiveness in delivering drugs [28-31]. The same purpose is placed on the measuring of zeta potential: with the surface-modified liposomes, their ability to increase the circulation time in the bloodstream relies on the coating moieties [32,33]. By measuring zeta potential, the results can offer information about the surface modifying process [34]. Representative graphs of particle size distribution and zeta potential resulting in LP versus PTX-ANA-LP are shown in Figure $1 \mathrm{a}, \mathrm{b}$. From a general point of view, the diameter of the dual drug co-loaded LP ranged between 100-200 $\mathrm{nm}$ and possessed longer blood retention; therefore it is more suitable for the accumulation of the liposomal system at tumor sites, relative to those that are out of the range (those with a size larger than $300 \mathrm{~nm}$ can accumulate in the spleen, while those smaller than $40 \mathrm{~nm}$ can be taken up by the liver, and both are subjected to easy elimination) [35-37]. The results of $170.1 \pm 13.5 \mathrm{~nm}$ with PDI $0.453 \pm 0.021$ and $189.0 \pm 22.1 \mathrm{~nm}$ with PDI $0.464 \pm 0.059$ for LP and PTX-ANA-LP, respectively, the prepared structure indicated a good potential for tumor tissue distribution of this delivery system.

a)

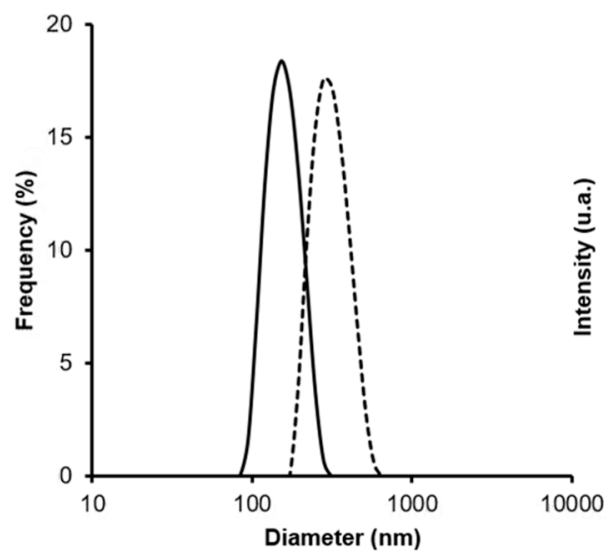

b)

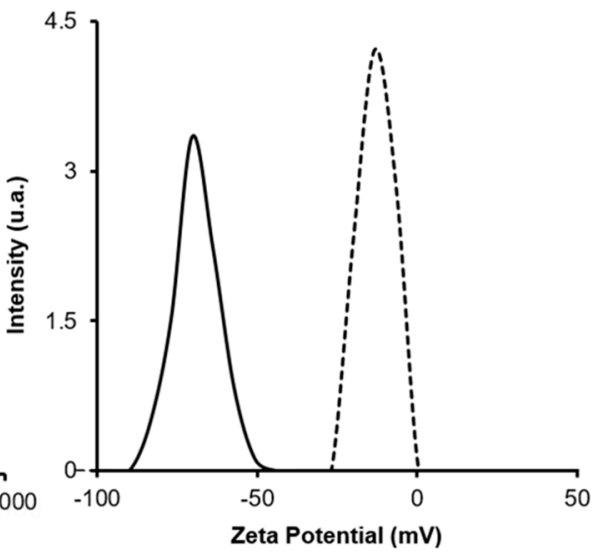

Figure 1. (a) Size distribution and (b) zeta potential of liposome (solid line) and PTX-ANA co-loaded liposome (dashed line).

On the other hand, the stability of nanoparticles in physiological conditions is reflected by zeta potential. In general, a zeta potential that is either lower than $-30 \mathrm{mV}$ or higher than $30 \mathrm{mV}$ could cause all the particles in the suspension to repel each other [38,39]. The zeta potentials of PTX-ANA-LP was found to be $-11.45 \pm 1.48 \mathrm{mV}$, which were all less negative than that of the blank LP $(-68.8 \pm 0.55 \mathrm{mV})$. These indicated that the co-delivery of hydrophilic and hydrophobic drugs exerted profound effects on zeta potential (changed from $-68.8 \mathrm{mV}$ up to $\sim-12 \mathrm{mV}$ ). 


\subsubsection{Morphology Observation}

Interpreting the TEM results shown in Figure 2, the morphologies of the blank LP and PTX-ANA-LP were confirmed to possess spherical shapes with a smaller diametrical range than $200 \mathrm{~nm}$, without aggregation or fusion, which were correlated with the values of the DLS measurement. Taken together, these results suggested that the advantage of the prepared dual drug co-loaded liposome is the ability to effectively penetrate tumors and accumulate at cancer cells' sites, which was established by the liposomes' sufficiently small particle size.

a)

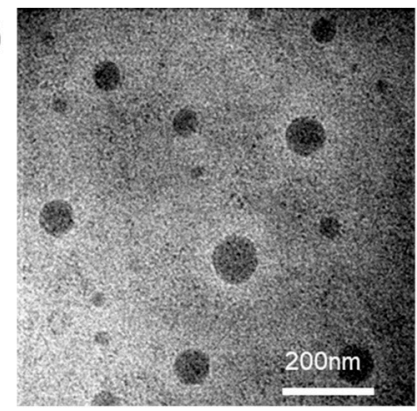

c)

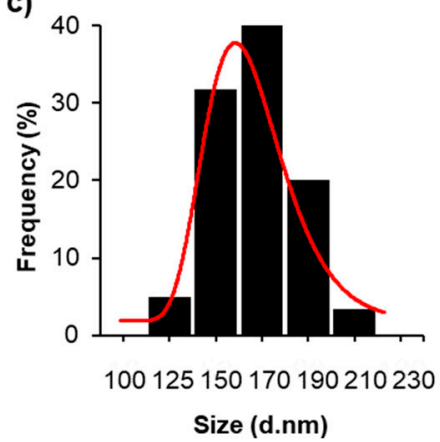

b)

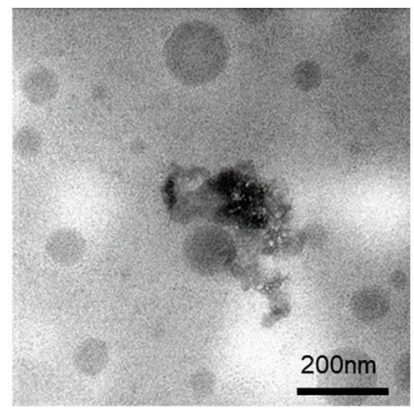

d)

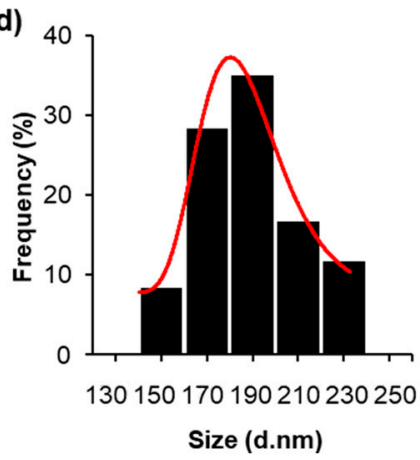

Figure 2. Transmission electron microscope image and particle size distribution of $(\mathbf{a}, \mathbf{c})$ LP and $(\mathbf{b}, \mathbf{d})$ PTX-ANA-LP.

\subsection{Drug Entrapment Efficiency and Loading Capacity}

Encapsulation of drugs in liposomes is also an important feature to be considered. Indeed, the efficiency of a chemotherapeutic treatment directly results from the ability of chemotherapeutic agents to reach the cancerous cells; within this context, liposomes must be able to carry a number of drugs that correspond to the one prescribed as part of the treatment. Furthermore, precedent studies have established the importance of encapsulation capacity: a large quantity of encapsulated drugs leads to a larger amount of drugs released at the sites of interest. Thus liposomes are well-adapted to the transportation of chemotherapeutic agents when they can be considered as one of the most efficient drug delivery systems in this aspect $[40,41]$.

EE results found within the framework of this study were $54.8 \pm 0.46 \%$ and $10.1 \pm 0.75 \%$, for PTX and ANA contained in the liposomes, respectively. Concerning DL, the following percentages were found: $2.82 \pm 0.76 \%$ for PTX encapsulation and $3.79 \pm 0.25 \%$ for ANA. In comparison with other studies, Rodallec et al. developed co-loaded docetaxel and trastuzumab into a stealth immunoliposome to achieve more efficient drug delivery in breast cancer. Their results showed that the EE of docetaxel in LP using phosphatidylcholine was $53 \pm 4 \%$ [42]. With the same taxane-based regimen, the prepared LP showed a satisfying encapsulation rate for PTX (according to previous studies, a higher percentage should be easily reachable), although the encapsulation rate of ANA was quite low. 


\subsection{In Vitro Drug Release of Multi-Drug Loaded Liposome}

Concerning the physical aspect of materials, there were no differences established between PTX and ANA in terms of physical aspects when loading them, which can be explained as due to the fact that both drugs are largely hydrophobic and behave the same in the process of encapsulation, i.e., by spontaneous hydrophobic interaction in an aqueous solution. The effects of the roughly 3-fold increase in molecular weight and slight increase in the structure of the two drugs when encapsulating them into the liposomes were negligible according to the results. This means that these two drugs act the same if co-loaded. The release profiles of free drugs and dual-drugs from LP were established to assess the release behavior of the prepared dual-drug loaded liposome formulation. As shown in Figure 3, no initial burst release phenomenon was observed for both drugs. The drugs (PTX and ANA) released in a sustained manner from the LP for during the entire $72 \mathrm{~h}$ study period. It has to be noted that PTX and ANA have different release patterns: in the later period of the release study, PTX was released relatively faster than ANA, which was released slowly until the end of the study period. For example, at the $48 \mathrm{~h}$ mark, approximately $49.19 \pm 3.0 \%$ of PTX was released compared to of $29.16 \pm 4.0 \%$ of ANA from the LP. By $72 \mathrm{~h}, 49.02 \pm 3.64 \%$ of PTX was released from the LP, whereas only $35.3 \pm 8.0 \%$ of ANA was released during the same period. The difference in the release profile among the two drugs might be due to different hydrophobicity and positions of the drugs in the lipid bilayer. In comparison, free PTX release would reach $94.79 \%$ after $72 \mathrm{~h}$, and ANA was complete released by $72 \mathrm{~h}$. A similar trend was described in the study of Lei et al., where the initial release of PTX from the liposome was only $52 \%$ within $72 \mathrm{~h}$ in $\mathrm{pH} 7.4$ conditions [43]. Zidan et al. reported that the initial release of ANA from poly(D,L-lactic-co-glycolic acid)-based microspheres was less than $35 \%$ for $36 \mathrm{~h}$

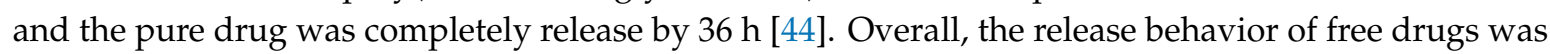
significantly faster than drugs loaded in LP, which means that the ratio of drug release was dependent on the LP. Therefore, drugs-loaded LP may increase drug accumulation into tumor sites and sustained release patterns for both drugs would be beneficial for efficient cancer therapy.

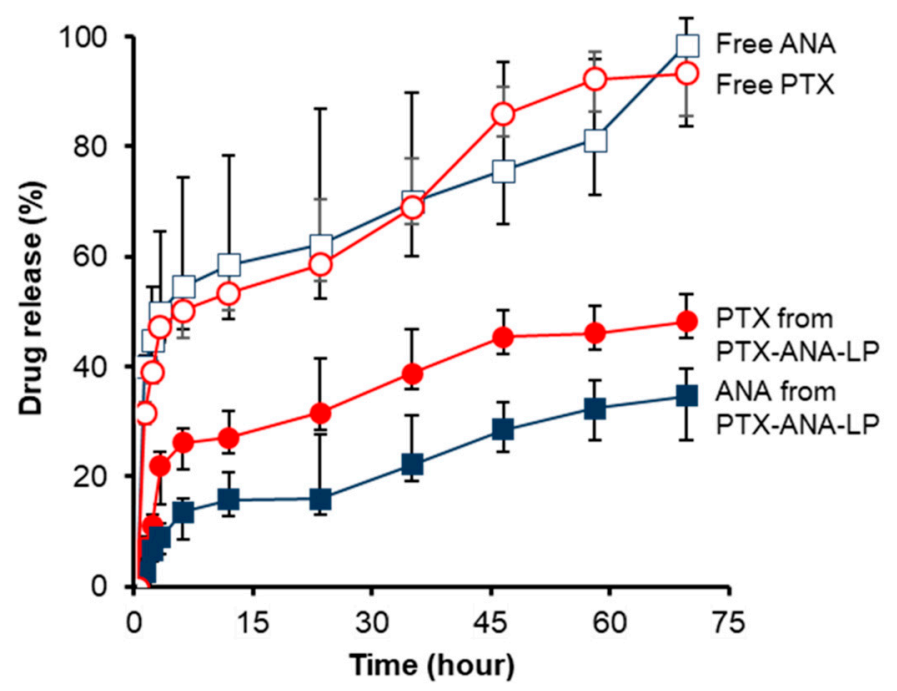

Figure 3. Release profiles of free PTX, free ANA, and PTX and ANA from PTX-ANA-LP at $37^{\circ} \mathrm{C}$ in phosphate buffered saline (PBS, $\mathrm{pH}=7.4 ; n=3$, mean \pm standard deviation).

\subsection{In Vitro Cytotoxicity}

It is known that a combination of drugs can help increase the effectiveness of treatment. In this study, WST assays in MCF-7 cell lines were carried out to evaluate the cytotoxicity and combination efficiency caused by PTX and ANA (Figure 4). As shown in Figure 4b, the cell proliferation study indicated that there was no significant difference between different LP concentrations, in the range of doses of $10-50 \mu \mathrm{g} / \mathrm{mL}$. The WST assays once again confirmed the biocompatibility of LP, as almost 
$90 \%$ of the MCF-7 cells were still viable at the highest concentration of LP $(100 \mu \mathrm{g} / \mathrm{mL})$ (Figure $4 \mathrm{~b})$. This demonstrated that the growth of the cells was significantly inhibited when they were treated with single or dual-drug loaded LP. The dose-dependent cytotoxicities of PTX, ANA, and PTX-ANA in the free forms and co-loaded into liposomes were observed when individually incubating at a concentration of $1 \mu \mathrm{g} / \mathrm{mL}$ with the MCF-7 cell line. As expected, the combination of PTX-ANA substantially reduced the viability of cancer cells. As shown in Figure 4a, the MCF-7 cancer cells were observed to retain their shape almost entirely after exposure to $1 \mu \mathrm{g} / \mathrm{mL}$ free ANA; meanwhile, at the concentration of $1 \mu \mathrm{g} / \mathrm{mL}$ free PTX and free PTX-ANA, cells were observed to lose their entire shape, which was correlated with the values of the IN Cell Analyzer measurement. A similar trend was found in the combination of LP: the cell viability after exposure to ANA-LP was higher than PTX-LP and lower when treated with combined dual-drugs in LP. The lower cytotoxicity performed on the MCF-7 cells by ANA in both free form and LP loaded form could be explained by the mechanism of action of ANA. ANA has been well-known as an aromatase inhibitor while MCF-7 cells express aromatase at very low levels; hence ANA might exhibit no remarkable Aromatase inhibitor (AI)-responsive action on these cells [45]. Although ANA might respond to the ER $\alpha$ gene expressed in MCF-7 cells, the low viability of the cells could have been caused due to there being not enough toxic-agents. By contrast, when co-loaded and co-delivered with PTX, ANA might act as an ER $\alpha$ ligand and target MCF-7 cells, after which PTX would cause death to these cells by inhibiting the cell division [2,11]. This confirmed that the combination of PTX and ANA enhances the cytotoxicity of ANA.

Free PTX, free ANA, and free PTX-ANA showed a cell viability of $17 \%, 51 \%$, and $15 \%$, respectively, while the PTX-ANA co-loaded liposome formulation exhibited approximately $69 \%$ viability of cells, indicating a superior controlled and sustained release of therapeutic drugs. In summary, free drugs easily diffuses into the cell membrane whereas drugs loaded into LP have a specific cellular uptake and release the drug in a systemized manner. Therefore, the developed liposomes co-encapsulating PTX and ANA can be regarded as valuable for planning new therapeutic strategies for breast cancer treatment. 

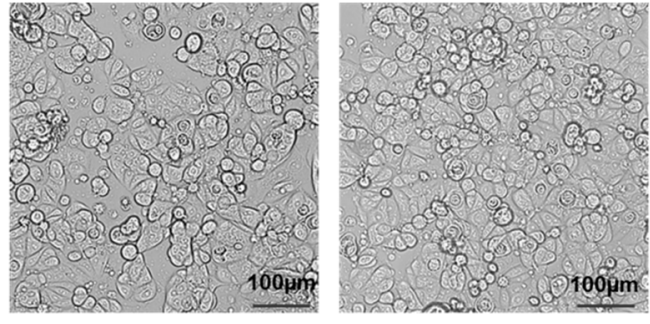

B
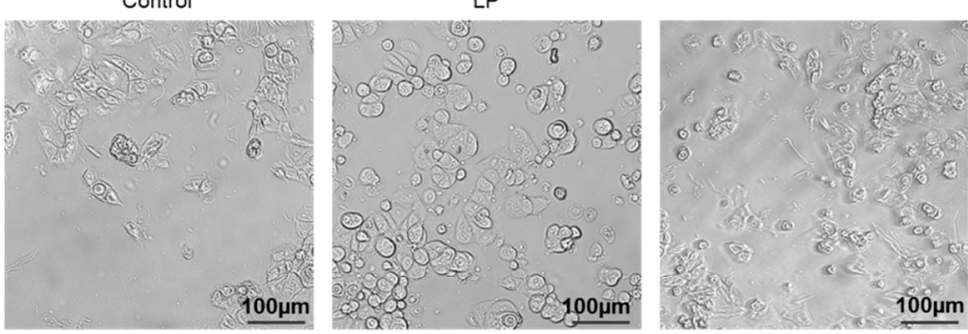

Free ANA

C
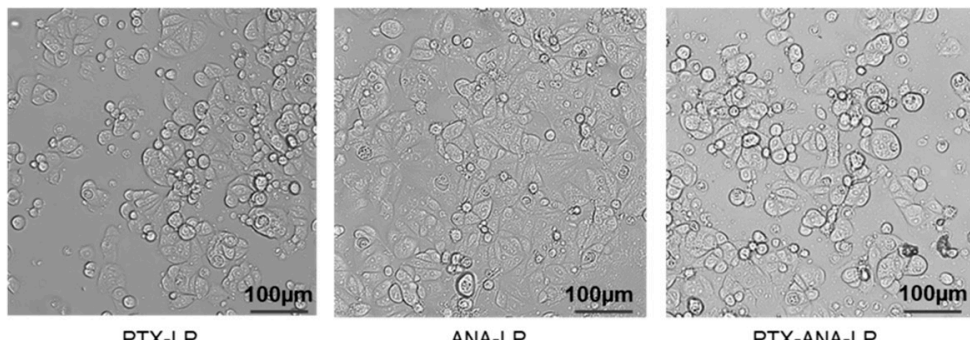

(a)
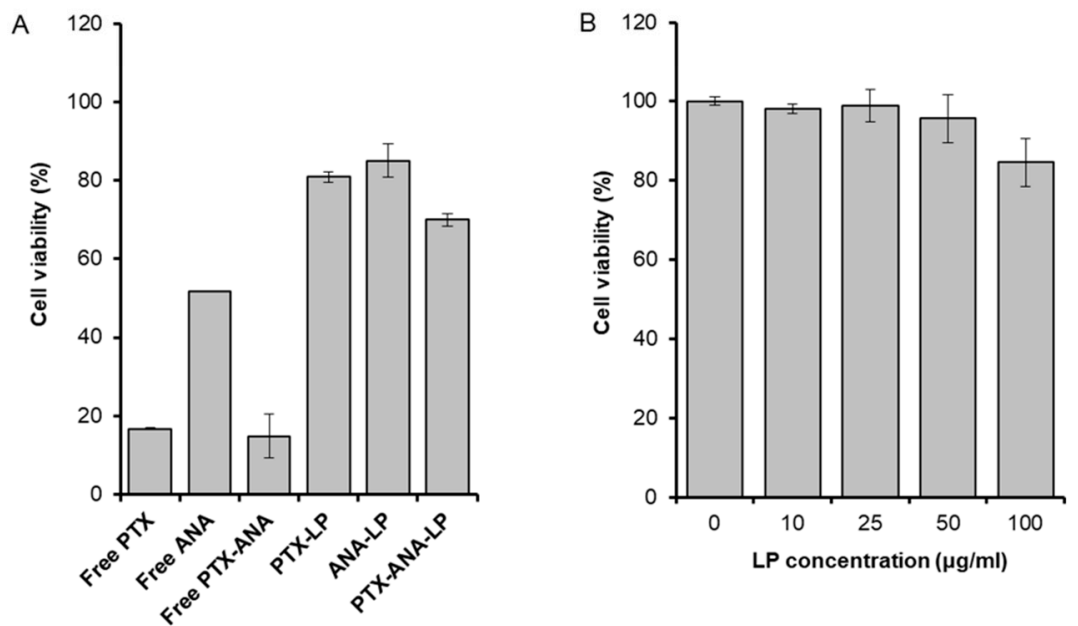

(b)

Figure 4. (a) Images of c-7 cells incubated with (A) Control, LP (100 $\mu \mathrm{g} / \mathrm{mL})$, (B) free PTX, free ANA and free PTX-ANA, and (C) PTX-LP, ANA-LP and PTX-ANA-LP for $24 \mathrm{~h}$ at a concentration of $1 \mu \mathrm{g} / \mathrm{mL}$ (scale bar $=100 \mathrm{~nm}$ ). (b) Viability of MCF-7 cells incubated with (A) free PTX, free ANA, free PTX-ANA, PTX-LP, ANA-LP and PTX-ANA-LP at a concentration of $1 \mu \mathrm{g} / \mathrm{mL}$ and (B) LP at different concentrations for $24 \mathrm{~h}$. The data represent the mean values \pm the standard deviation (SD) $(n=4)$.

\section{Conclusions}

In conclusion, PTX and ANA co-loaded LP was successfully developed and characterized for its activity against a human breast cancer MCF-7 cell line. PTX-ANA-LP was spherical in shape with a diameter around $189 \mathrm{~nm}$, which would be suitable for in vivo drug release, and exhibited a controlled release profile for up to $72 \mathrm{~h}$ for both drugs $(49.02 \pm 3.64 \%$ and $35.3 \pm 8.0 \%$ of PTX and 
ANA were released from LP, respectively). In addition, PTX-ANA-LP showed a potent anticancer effect in MCF-7 at a concentration of $1 \mu \mathrm{g} / \mathrm{mL}$. Particularly, it was clear that PTX-ANA co-loaded into LP remarkably controlled and prolonged drugs release, which was determined by WST assay. These findings suggested a new approach to breast cancer treatment that consists of the combination therapy of PTX and ANA in liposomes based on ER response. Further study should be conducted to clarify the interaction mechanism of PTX and ANA when being co-delivered.

Supplementary Materials: The following are available online at http://www.mdpi.com/2227-9717/8/9/1110/s1, Figure S1: flow chart on the production of LP.

Author Contributions: Conceptualization, M.T.V. and N.H.N.; methodology, V.T.L. and T.D.C.; validation, D.T.D.N. and N.H.N.; formal analysis, T.L.-B.P., T.N.D., V.T.L. and T.H.N.; investigation, N.T.T.L.; data curation, T.D.L.; writing — original draft preparation, M.T.V.; writing—review and editing, M.T.V. and N.T.T.L.; supervision, N.T.T.L. All authors have read and agreed to the published version of the manuscript.

Funding: This research was funded by the Vietnam National Foundation for Science and Technology Development (NAFOSTED) under grant number 104.06-2018.320.

Conflicts of Interest: The authors declare no conflict of interest.

\section{References}

1. Semreen, M.H.; Alniss, H.; Cacciatore, S.; El-Awady, R.; Mousa, M.; Almehdi, A.M.; El-Huneidi, W.; Zerbini, L.; Soares, N.C. GC-MS based comparative metabolomic analysis of MCF-7 and MDA-MB-231 cancer cells treated with Tamoxifen and/or Paclitaxel. Biochem. Mol. Biol. 2020, 225, 103875. [CrossRef] [PubMed]

2. Alqahtani, F.Y.; Aleanizy, F.S.; El Tahir, E.; Alkahtani, H.M.; AlQuadeib, B.T. Paclitaxel. In Profiles of Drug Substances, Excipients and Related Methodology; Elsevier: Amsterdam, The Netherlands, 2019; Volume 44, pp. 205-238.

3. Crown, J.; O'Leary, M.; Ooi, W.S. Docetaxel and paclitaxel in the treatment of breast cancer: A review of clinical experience. Oncologist 2004, 9, 24-32. [CrossRef] [PubMed]

4. Paridaens, R.; Biganzoli, L.; Bruning, P.; Klijn, J.; Gamucci, T.; Houston, S.; Coleman, R.; Schachter, J.; Van Vreckem, A.; Sylvester, R. Paclitaxel versus doxorubicin as first-line single-agent chemotherapy for metastatic breast cancer: A European Organization for Research and Treatment of Cancer Randomized Study with cross-over. J. Clin. Oncol. 2000, 18, 724-733. [CrossRef] [PubMed]

5. Stage, T.B.; Bergmann, T.K.; Kroetz, D.L. Clinical pharmacokinetics of paclitaxel monotherapy: An updated literature review. Clin. Pharmacokinet. 2018, 57, 7-19. [CrossRef] [PubMed]

6. De Weger, V.A.; Beijnen, J.H.; Schellens, J.H. Cellular and clinical pharmacology of the taxanes docetaxel and paclitaxel-A review. Anticancer Drugs 2014, 25, 488-494. [CrossRef] [PubMed]

7. Smith, I.E.; Dowsett, M. Aromatase inhibitors in breast cancer. New Engl. J. Med. 2003, 348, 2431-2442. [CrossRef]

8. Geisler, J.; King, N.; Dowsett, M.; Ottestad, L.; Lundgren, S.; Walton, P.; Kormeset, P.; Lønning, PE. Influence of anastrozole (Arimidex), a selective, non-steroidal aromatase inhibitor, on in vivo aromatisation and plasma oestrogen levels in postmenopausal women with breast cancer. Br. J. Cancer 1996, 74, 1286-1291. [CrossRef]

9. Geisler, J.G.; Stubbs, L.J.; Wasserman, W.W.; Mucenski, M.L. Molecular cloning of a novel mouse gene with predominant muscle and neural expression. Mamm. Genome 1998, 9, 274-282. [CrossRef]

10. Geisler, J.r.; Haynes, B.; Anker, G.; Dowsett, M.; Lønning, P.E. Influence of letrozole and anastrozole on total body aromatization and plasma estrogen levels in postmenopausal breast cancer patients evaluated in a randomized, cross-over study. J. Clin. Oncol. 2002, 20, 751-757. [CrossRef]

11. Ingle, J.N.; Cairns, J.; j Suman, V.J.; Shepherd, L.E.; Fasching, P.A.; Hoskin, T.L.; Singh, R.J.; Desta, Z.; Kalari, K.R.; Ellis, M.J.; et al. Anastrozole has an association between degree of estrogen suppression and outcomes in early breast cancer and is a ligand for estrogen receptor $\alpha$. Clin. Cancer Res. 2020, 26, 2986-2996. [CrossRef]

12. Albain, K.S.; Nag, S.M.; Calderillo-Ruiz, G.; Jordaan, J.P.; Llombart, A.C.; Pluzanska, A.; Rolski, J.; Melemed, A.S.; Reyes-Vidal, J.M.; Sekhon, J.S. Gemcitabine plus paclitaxel versus paclitaxel monotherapy in patients with metastatic breast cancer and prior anthracycline treatment. J. Clin. Oncol. 2008, 26, 3950-3957. [CrossRef] [PubMed] 
13. De Vita, F.; Borg, C.; Farina, G.; Geva, R.; Carton, I.; Cuku, H.; Wei, R.; Muro, K. Ramucirumab and paclitaxel in patients with gastric cancer and prior trastuzumab: Subgroup analysis from RAINBOW study. Future Oncol. 2019, 15, 2723-2731. [CrossRef] [PubMed]

14. Valery, S.; Chouaid, C.; Rousseau-Bussac, G.; Monnet, I.; Bilger, G.; Boré, P.; Pinsolle, J.; Descourt, R.; Geier, M.; Toffart, A. Efficacy of weekly paclitaxel-bevacizumab combination in advanced non squamous non-small cell lung cancer (NSCLC) progressing after immune checkpoint inhibitors-AVATAX, a retrospective multicentric study: Preliminary data. Ann. Oncol. 2019, 30, xi29. [CrossRef]

15. Watanabe, N.; Ootawa, Y.; Kodama, K.; Kaide, A.; Ootsuka, N.; Matsuoka, J. Concurrent administration of chemo-endocrine therapy for postmenopausal breast cancer patients. Breast Cancer 2010, 17, 247-253. [CrossRef]

16. Sato, T.; Nakagawa, T.; Kuwayama, T.; Kubota, K.; Suzuki, S.; Sugihara, K. A case of inflammatory breast cancer responding to anastrozole. Gan Kagaku Ryoho. Cancer Chemother. 2009, 36, 2477-2479.

17. Mota, L.D.G.; de Barros, A.L.; Fuscaldi, L.L.; de Oliveira, M.C.; Cardoso, V.N. Long-Circulating and pH-Sensitive Liposome Preparation Trapping a Radiotracer for Inflammation Site Detection. J. Nanosci. Nanotechnol. 2015, 15, 4149-4158. [CrossRef]

18. Zhang, H.; Xiao, Y.; Cui, S.; Zhou, Y.; Zeng, K.; Yan, M.; Zhao, C. Novel Galactosylated Poly(ethylene glycol)-Cholesterol for Liposomes as a Drug Carrier for Hepatocyte-Targeting. J. Nanosci. Nanotechnol. 2015, 15, 4058-4069. [CrossRef]

19. Gunay, M.S.; Ozer, A.Y.; Erdogan, S.; Bodard, S.; Baysal, I.; Gulhan, Z.; Guilloteau, D.; Chalon, S. Development of Nanosized, Pramipexole-Encapsulated Liposomes and Niosomes for the Treatment of Parkinson's Disease. J. Nanosci. Nanotechnol. 2017, 17, 5155-5167. [CrossRef]

20. Ahmed, K.S.; Hussein, S.A.; Ali, A.H.; Korma, S.A.; Lipeng, Q.; Jinghua, C. Liposome: Composition, characterisation, preparation, and recent innovation in clinical applications. J. Drug Target. 2019, 27, 742-761. [CrossRef]

21. Tran, P.; Lee, S.-E.; Kim, D.-H.; Pyo, Y.-C.; Park, J.-S. Recent advances of nanotechnology for the delivery of anticancer drugs for breast cancer treatment. J. Pharm. Investig. 2019, 1-10. [CrossRef]

22. Chen, S.; Auriat, A.; Koudrina, A.; DeRosa, M.; Cao, X.; Tsai, E.C. Nano-engineering Nanoparticles for Clinical Use in the Central Nervous System: Clinically Applicable Nanoparticles and Their Potential Uses in the Diagnosis and Treatment of CNS Aliments. In Nanoengineering Materials for Biomedical Uses; Springer: New York, NY, USA, 2019; pp. 125-145.

23. Wesolowski, R.; Ramaswamy, B. Gene expression profiling: Changing face of breast cancer classification and management. Gene Expr. 2011, 15, 105-115. [CrossRef] [PubMed]

24. Angeloni, S.; Martin, M.; Garcia-Morales, P.; Castro-Galache, M.; Ferragut, J.; Saceda, M. Regulation of estrogen receptor-alpha expression by the tumor suppressor gene p53 in MCF-7 cells. 2004, 180, 497-504. J. Endocrinol. 2004, 180, 497-504. [CrossRef] [PubMed]

25. Shashni, B.; Nagasaki, Y. Nitroxide radical-containing nanoparticles attenuate tumorigenic potential of triple negative breast cancer. Biomaterials 2018, 178, 48-62. [CrossRef] [PubMed]

26. Ansari, S.A.; Matricardi, P.; Meo, C.D.; Alhaique, F.; Coviello, T. Evaluation of rheological properties and swelling behaviour of sonicated scleroglucan samples. Molecules 2012, 17, 2283-2297. [CrossRef] [PubMed]

27. Yang, T.; Cui, F.-D.; Choi, M.-K.; Lin, H.; Chung, S.-J.; Shim, C.-K.; Kim, D.-D. Liposome formulation of paclitaxel with enhanced solubility and stability. Drug Deliv. 2007, 14, 301-308. [CrossRef]

28. Le, N.T.T.; Pham, L.P.T.; Nguyen, D.H.T.; Le, N.H.; Tran, T.V.; Nguyen, C.K.; Nguyen, D.H. Liposome-Based Nanocarrier System for Phytoconstituents. In Novel Drug Delivery Systems for Phytoconstituents; CRC Press: Boca Raton, FL, USA, 2019; pp. 45-68.

29. Thi, N.T.N.; Nguyen, D.H. Hollow mesoporous silica nanoparticles fabrication for anticancer drug delivery. Vietnam J. Sci. Technol. 2020, 58, 39.

30. Bi, Y.; Lv, B.; Li, L.; Lee, R.J.; Xie, J.; Qiu, Z.; Teng, L. A Liposomal Formulation for Improving Solubility and Oral Bioavailability of Nifedipine. Molecules 2020, 25, 338. [CrossRef]

31. Nguyen-Thi, N.-T.; Tran, P.; Phuong, L.; Le, N.T.T.; Cao, M.-T.; Nguyen, N.T.; Nguyen, C.H.; Nguyen, D.-H.; Than, V.T.; Le, Q.T. The Engineering of Porous Silica and Hollow Silica Nanoparticles to Enhance Drug-loading Capacity. Processes 2019, 7, 805. [CrossRef] 
32. Yaroslavov, A.; Efimova, A.; Smirnova, N.; Erzunov, D.; Lukashev, N.; Grozdova, I.; Melik-Nubarov, N. A novel approach to a controlled opening of liposomes. Colloids Surf. B Biointerfaces 2020, 190, 110906. [CrossRef]

33. Sakai-Kato, K.; Yoshida, K.; Izutsu, K.-i. Effect of surface charge on the size-dependent cellular internalization of liposomes. Chem. Phys. Lipids 2019, 224, 104726. [CrossRef]

34. Ibaraki, H.; Kanazawa, T.; Oogi, C.; Takashima, Y.; Seta, Y. Effects of surface charge and flexibility of liposomes on dermal drug delivery. J. Drug Deliv. Sci. Technol. 2019, 50, 155-162. [CrossRef]

35. Brandelli, A. The interaction of nanostructured antimicrobials with biological systems: Cellular uptake, trafficking and potential toxicity. Food Sci. Hum. Wellness 2020, 9, 8-20. [CrossRef]

36. Le, N.T.T.; Cao, V.D.; Nguyen, T.N.Q.; Le, T.T.H.; Tran, T.T.; Hoang Thi, T.T. Soy Lecithin-Derived Liposomal Delivery Systems: Surface Modification and Current Applications. Int. J. Mol. Sci. 2019, 20, 4706. [CrossRef] [PubMed]

37. Le, N.T.T.; Thi, Y.N.N.; Thi, B.L.P.; Hoang, N.L.; Nguyen, C.K.; Nguyen, D.H. Nanoliposomes as an Efficient Drug Carrier System for Paclitaxel Delivery. In Proceedings of the International Conference on the Development of Biomedical Engineering in Vietnam, Ho Chi Minh City, Vietnam, 27-29 June 2018; pp. 193-196.

38. Drummond, D.C.; Noble, C.O.; Hayes, M.E.; Park, J.W.; Kirpotin, D.B. Pharmacokinetics and in vivo drug release rates in liposomal nanocarrier development. J. Pharm. Sci. 2008, 97, 4696-4740. [CrossRef]

39. Nguyen, T.L.; Nguyen, T.H.; Nguyen, D.H. Development and in vitro evaluation of liposomes using soy lecithin to encapsulate paclitaxel. Int. J. Biomater. 2017, 2017, 1-7. [CrossRef] [PubMed]

40. Xiao, H.; Yan, L.; Dempsey, E.M.; Song, W.; Qi, R.; Li, W.; Huang, Y.; Jing, X.; Zhou, D.; Ding, J. Recent progress in polymer-based platinum drug delivery systems. Prog. Polym. Sci. 2018, 87, 70-106. [CrossRef]

41. Le, N.T.T.; Nguyen, T.N.Q.; Cao, V.D.; Hoang, D.T.; Ngo, V.C.; Thi, H.; Thanh, T. Recent Progress and Advances of Multi-Stimuli-Responsive Dendrimers in Drug Delivery for Cancer Treatment. Pharmaceutics 2019, 11, 591. [CrossRef] [PubMed]

42. Rodallec, A.; Brunel, J.-M.; Giacometti, S.; Maccario, H.; Correard, F.; Mas, E.; Orneto, C.; Savina, A.; Bouquet, F.; Lacarelle, B. Docetaxel-trastuzumab stealth immunoliposome: Development and in vitro proof of concept studies in breast cancer. Int. J. Nanomed. 2018, 13, 3451. [CrossRef]

43. Lei, M.; Ma, G.; Sha, S.; Wang, X.; Feng, H.; Zhu, Y.; Du, X. Dual-functionalized liposome by co-delivery of paclitaxel with sorafenib for synergistic antitumor efficacy and reversion of multidrug resistance. Drug Deliv. 2019, 26, 262-272. [CrossRef]

44. Zidan, A.S.; Sammour, O.A.; Hammad, M.A.; Megrab, N.A.; Hussain, M.D.; Khan, M.A.; Habib, M.J. Formulation of anastrozole microparticles as biodegradable anticancer drug carriers. Aaps Pharmscitech 2006, 7, E38-E46. [CrossRef]

45. Zhou, D.; Pompon, D.; Chen, S.A. Stable expression of human aromatase complementary DNA in mammalian cells: A useful system for aromatase inhibitor screening. Cancer Res. 1990, 50, 6949-6954. [PubMed] 